$\xi=-1$

\title{
Design of Dual Band Circular Microstrip Patch Antenna with Slot for WLAN Applications
}

\author{
L. Nageswara Rao ${ }^{1 *}$, B. Ramesh ${ }^{2}$, V. Santhosh Kumar ${ }^{3}$ \\ ${ }^{I}$ Department of Electronics and Communication Engineering, CVR College of Engineering, Hyderabad, India \\ ${ }^{2}$ Department of Electronics and Communication Engineering, CVR College of Engineering, Hyderabad, India \\ ${ }^{3}$ Department of Electronics and Communication Engineering, St. Mary's Group of Institutions, Hyderabad, India \\ *Corresponding author E-mail: lavurinagesh@gmail.com
}

\begin{abstract}
A composite double - band circular microstrip patch (MPA) with space opening for WLAN is intended. An investigated configuration is feasible for WLAN applications. An investigated configuration includes the circular patch and $\pi$ - space resonator. The compact in the antenna size for the lower band is attained by adopting a $\pi$ - shaped opening space on the ground plane. By balancing the model specifications, a circular patch resonator act at the primary band $(5.2 \mathrm{GHz})$ and the $\pi$ - space slot act at the secondary band $(2.4 \mathrm{GHz})$, while using the substrate substantial FR4 whichever carry dielectric constant of $4.4\left(\varepsilon_{r}\right)$. The arranged antenna configuration has small in size, less weight, reduced cost and acceptable isolation. Designed structure presents the return loss less than $-10 \mathrm{~B}$ and it is indicated with significant impedance matching, improved radiation pattern and good VSWR around 1 over the working bands. The investigated configuration is simulated and analyzed with HFSS.
\end{abstract}

Keywords: Circular patch; parasitic slot; dual band operation; miniaturization; WLAN.

\section{Introduction}

A dual-band microstrip patch antennas (MPA) are in the awesome request because of the fast advancement of remote correspondences towards the wireless network's applications. Just a while earlier, microstrip receiving wires [1]-[2] have asked for an enormous idea in modernized remote correspondence substance in light of their diverse fascinating appearance regarding little dissemination misfortune, less weight, low profile, available excitation, restricted in size and simplicity of produce in like way broad impedance transmission capacity. The patch antenna is an exceptionally fascinating engaging alternative for applications at remote correspondences. The distinct idea of MPAs filling in as round and hollow, rectangular, triangular, ring slot and hemispherical shapes [3] have been given in the literature. The circular and rectangular patch antennas are having the inherent advantages over the triangular, ring slot and half of the globe shapes.

A dual - band patch antenna model [3]-[7] to accomplish double frequency operations for WLAN applications is modelled in this configuration. A Suggested configuration includes patch resonator [8]-[10] and $\pi$ - shaped slot resonator [11]-[15]. These two oozing elements are significantly mutilated in sync; vibrate at higher and discretionary recurrences subsequently. Their radiation designs have diverse execution for remote correspondence applications. Keeping in mind the end goal to expand the operation extend, the radio wire must be expanded in measurement and size of a physical receiving wire. To lessen complexity, size, and structure of the antenna, this can be accomplished by etching a slot on the ground plane. The most commonly engaged microstrip antenna is circular shaped patch antenna. The Patch antenna is the capability to have emission diversity. On the off chance that the dielectric permittivi- ty of the substrate rises, the receiving wire bandwidth diminishes. Over the latest couple of generations, the movement of remote systems (WLAN) depicted with central attractions of a message with correspondence range. A prerequisite for remote LAN structure has extended up to the impression. Wireless medium for frequencies adjusting bands of the proposed circumstances must be predominant discernment before arranging a mobilized WLAN structure [16].The $2.45 \mathrm{GHz}$ recurrence band is without allowing for that direction ultimate extreme of remote systems models remains obstruction against alternate models and that utilize a similar kind of recurrence band. This $2.45 \mathrm{GHz}$ band is appropriated by IEEE $802.11 \mathrm{~b}$ regulations.5.25 GHz is employed by IEEE 802.11a [17] regulation and that is more phenomenal help immense speed WLAN.

In this way, a microstrip supplied line is considered to transfer the energy from one point to another point efficiently and furthermore directed toward preserving the strategic distance in distinction the openings [10]. The feed supplied line effectively incorporates with the antennas. The microstrip supplied line [18] has more flexibility and compactness than co axial feed line. The acceptance of microstrip line is easy to match and simple to create. The investigated circular dual band microstrip resonator is simulated and analyzed with HFSS. It is a viable fundamental full-wave electric and magnetic range analysis approach for subjective 3D dimensions perfect hardware professed that yields changes of basic Microsoft windows pictorial interface. The HFSS used to decide the parameters, for example, return loss, working recurrence, fields, and so on. To emphasize the configuration, the intended dual frequency circular patch with $\pi$-shaped antenna [15] is illuminated for WLAN. It includes the circular patch and $\pi$ - space resonators and these are the primary band $(5.2 \mathrm{GHz})$ and the secondary band $(2.4$ $\mathrm{GHz}$ ) subsequently. The arranged antenna configuration has small 
in size, less weight, reduced cost and acceptable isolation and can obtain dual - band operation with various radiation designs.

\section{Antenna configuration}

Fig. 1 describes the intended double frequency [7] circular patch [10] arrangement. It involves a circular patch and $\pi$ - space opening, the circular patch is located on the dielectric substrate and $\pi$ shaped slot is imprinted in a ground plane, both the emitting components are intensely well organized. These two elements oscillate at primary and secondary recurrences subsequently. The feed point is imprinted at a centre point of the substrate. The investigated structure is printed on both sides, one side is a circular patch and another side is a ground plane with parasitic space. The patch antenna resonators can be sustained by several models. The radio wire antenna is implemented by using a microstrip sustained line for the reason it is one of the simple approaches to fabricate. The supportive parameters of the $\pi$-shaped antenna are realized. The intended antenna is created with a substrate of FR4 with a thickness of $0.16 \mathrm{~cm}$ and relative permittivity is 4.4 .

A suggested antenna has a compact element and total configuration is about $4 \mathrm{~cm} \times 4 \mathrm{~cm} \times 0.16 \mathrm{~cm}$. Pursuance of dual - band circular patch antenna is situated on various factors such as feeding point, the diameter of a circular patch and parametric length of the parasitic slot. Also, antenna Pursuance builds upon outline and dimensions of the substrate. A circular resonator is the main component of WLAN structure. The inclination of WLAN structure is to design a compact and elementary antenna that offers small distortions with high bandwidth. The round fix has an extent of $\mathrm{R}=$ $1.4 \mathrm{~cm}$ and relative permittivity of $\mathrm{Er}=4.4$ as appeared in Figure 1 . The halfway purpose of the roundabout fix is settled over the inside line of the substrate with a balanced space $\mathrm{S} 1=19 \mathrm{~mm}$ which is offered to utilize the consolidating intensity of microstripmanaged line with round microstrip fix. The extent of the $50-\Omega$ matching feed has the dimensions of $\mathrm{W}_{\mathrm{f}}=0.3 \mathrm{~cm}$ and $\mathrm{L}_{\mathrm{f}}=2.1 \mathrm{~cm}$. The analytical operating frequency for circular resonator is determined [19] with consequent formula and analogous to $5.2 \mathrm{GHz}$ which is applicable for wireless LAN applications.

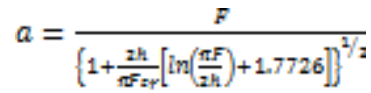

Here,

$$
F=\frac{8.791 \times 10^{2}}{f_{Y} \sqrt{\varepsilon_{x}}}
$$

In addition to that one more resonator being $\pi$ - arrangement space is adopted on the ground plane for the resolve of frequency $2.4 \mathrm{GHz}$ band [20]. The configuration of $\pi-$ slot is as conferred in Figure 1 . The lower band is attained by adopting a $\pi-$ slot. It is remarkable that by considering appropriate dielectric substrate [21], a compact size structure can be realized. Hence, the intended antenna is created with the FR4 material having dielectric constant 4.4. The layout for the lower stimulate $\pi$ - opening slot is incorporate the three space openings includes various breadth and equal dimension $\mathrm{W}_{\mathrm{S}}=0.05 \mathrm{~cm}$ in the point of Fig 1 , a $\pi$ - shaped space on the ground plane with balanced separation distance are $S_{2}$ $=26 \mathrm{~mm}$, various rectangular space lengths are $\mathrm{L}_{1}=2.0 \mathrm{~cm}$, $\mathrm{L}_{2}=\mathrm{L}_{3}=0.5 \mathrm{~cm}$. The centre point of the $\pi$ - slot is fixed to half of the ground plane representing as $S_{3}=11 \mathrm{~mm}$. By balancing the model parameters, the circular patch resonator and $\pi$ - space slot are acted at the primary band $(5.2 \mathrm{GHz})$ and the secondary band $(2.4 \mathrm{GHz})$ subsequently.

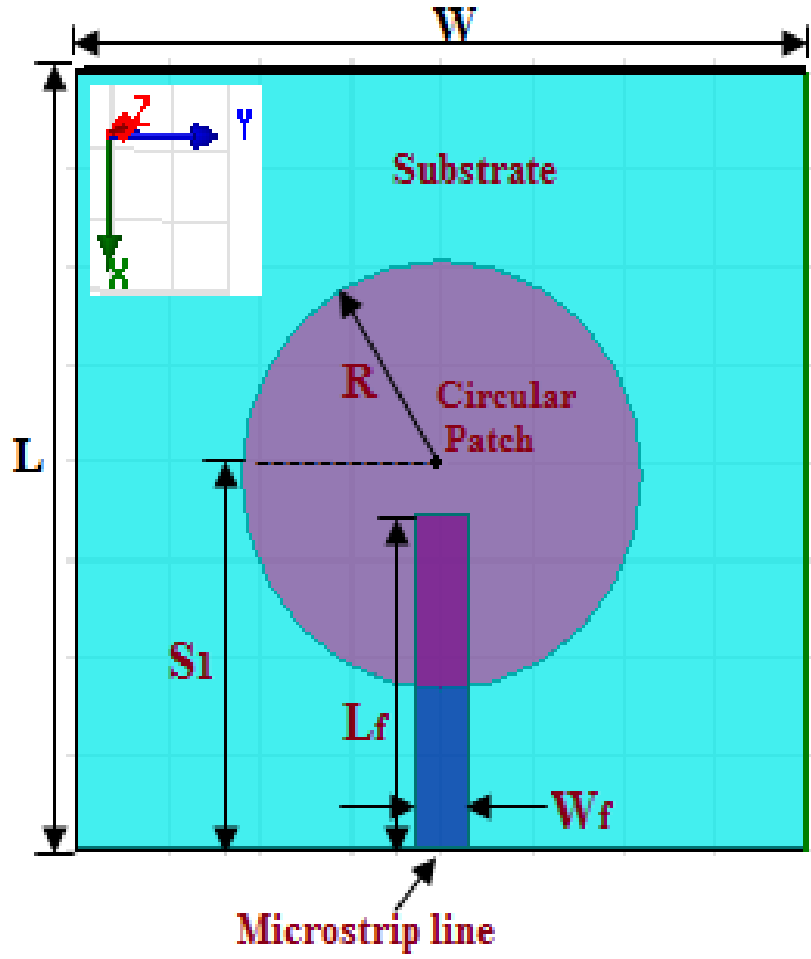

(a)

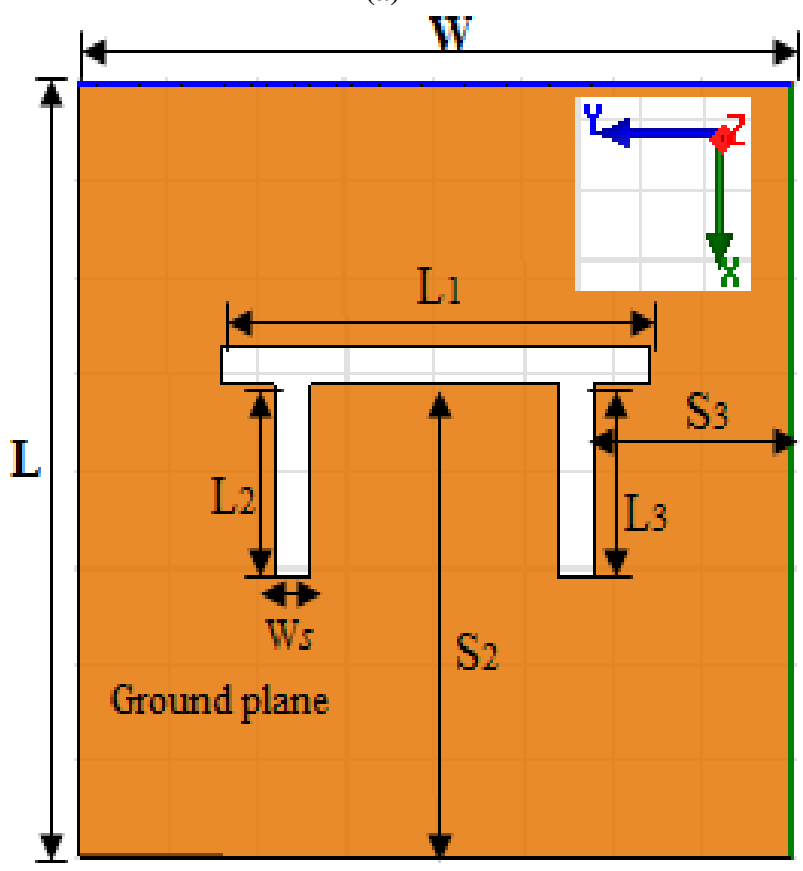

(b)

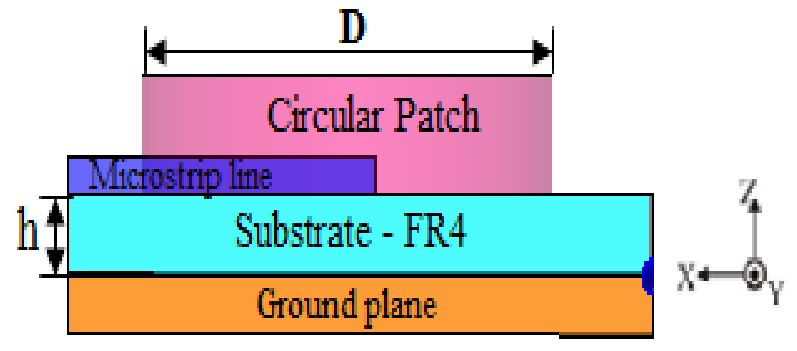

(c)

Fig. 1: Designed MPA: (a) Top view; (b) Bottom view; (c) cross sectional view 


\section{Simulated results and discussions}

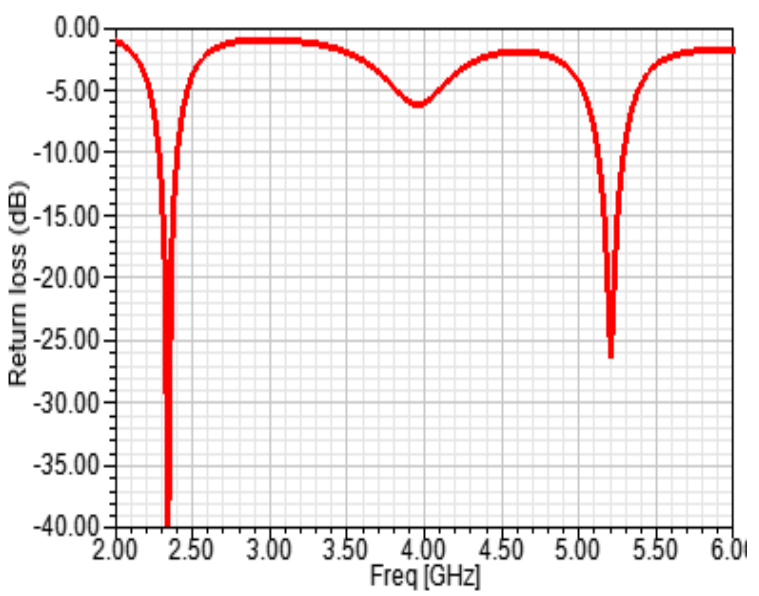

Fig. 2: Simulated return loss characteristics at $2.41 \mathrm{GHz}$ and $5.25 \mathrm{GHz}$

The return loss characteristics of simulated configuration are illustrated in figure 2 . The circular resonator and $\pi$ - space elements resonate with secondary and primary band consequently. It is watched return misfortune at $2.4 \mathrm{GHz}$ and $5.2 \mathrm{GHz}$ as $-40 \mathrm{~dB}$ and $-27 \mathrm{~dB}$ consequently. As a result, a simulated primary band attains a bandwidth of $4.20 \%(2330-2440 \mathrm{MHz})$ and secondary band attains a bandwidth of $4.01 \%$. The slot space resonates because of a circular resonator and there are no oscillations without patch component.

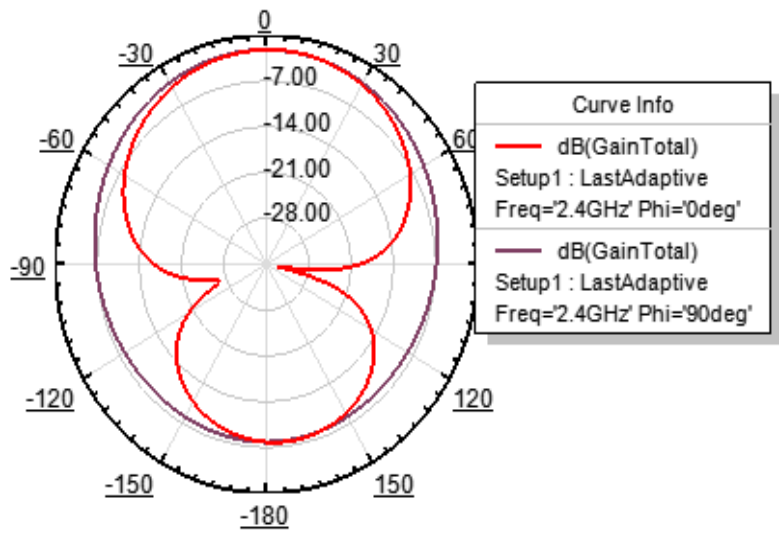

(a)

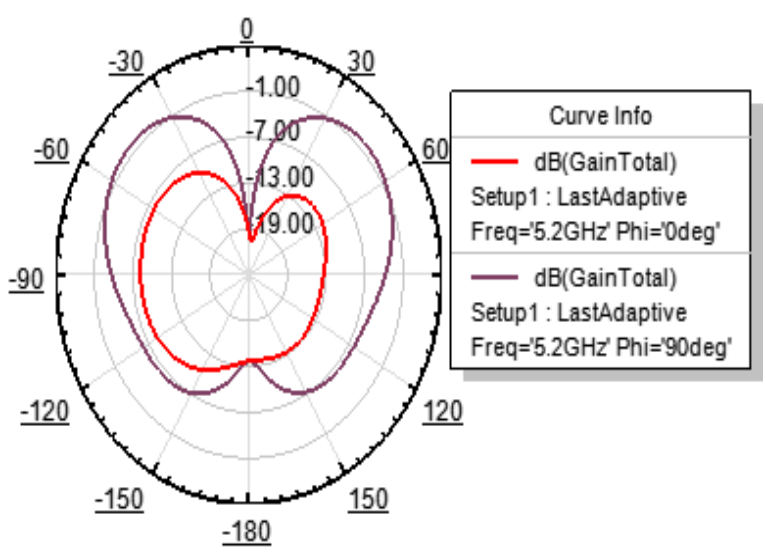

Fig. 3: Simulated radiation characteristics of CMPA
Figure 3 exhibits the radiation characteristics of suggested configuration. An intended configuration emits the most extreme towards the major direction at $5.25 \mathrm{GHz}$ and $\pi$ - opening slot resonator is radiating the waves in bidirectional at ISM range.

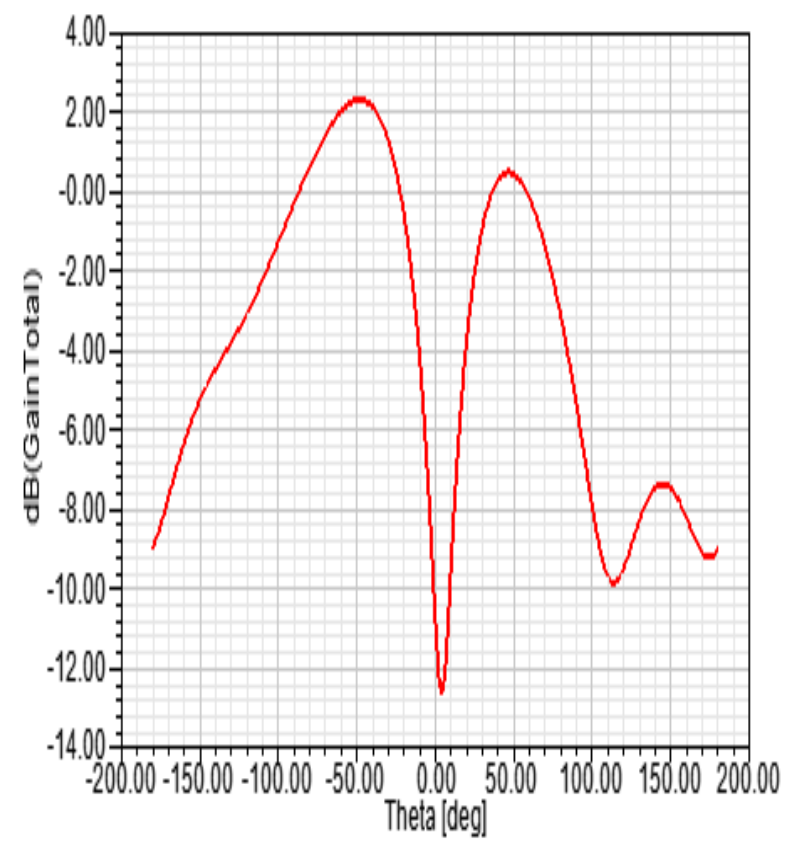

(a)

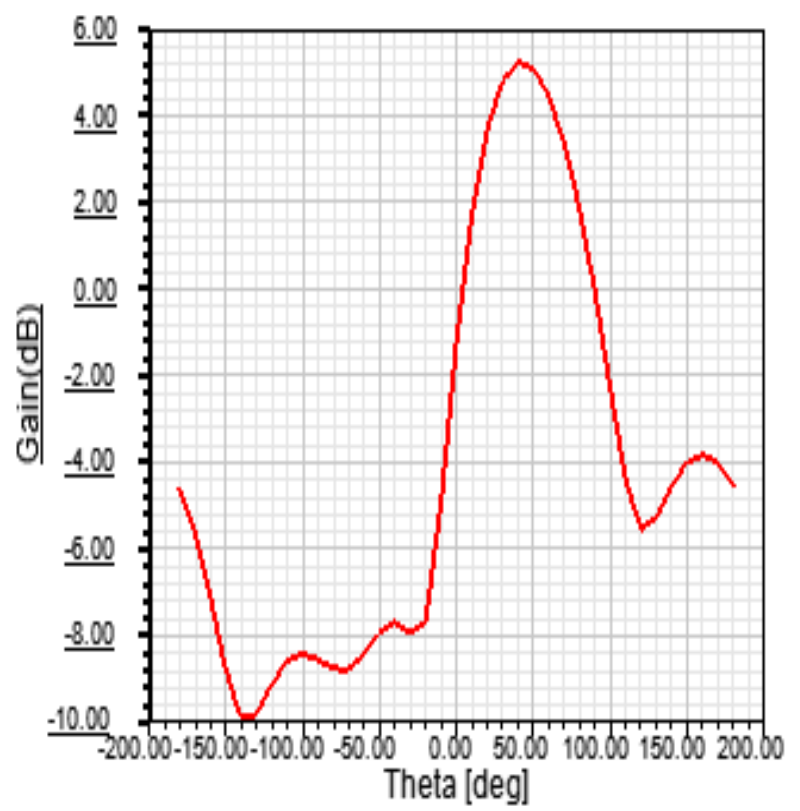

(b)

Fig. 4: Simulated Gain at $2.4 \mathrm{GHz}$ and $5.2 \mathrm{GHz}$

The intended configuration has the gain at $2.41 \mathrm{GHz}$ and 5.25 $\mathrm{GHz}$ as $2.6 \mathrm{dBi}$ and $4.9 \mathrm{dBi}$ consequently as represented in figure 4. The most extreme radiation is directed towards outside in both the recurrences. ISM and HYPERLAN recurrences are advisable for wireless communications.

Figure 5 demonstrates the VSWR of the involved model. It is portrayed as the examination of the error between the sustain line and load. For ideal case value of VSWR is 1 and for good impedance matching. The intended configuration has the VSWR value as 1.11 and 1.06 at $5.25 \mathrm{GHz}$ and $2.40 \mathrm{GHz}$ subsequently. 


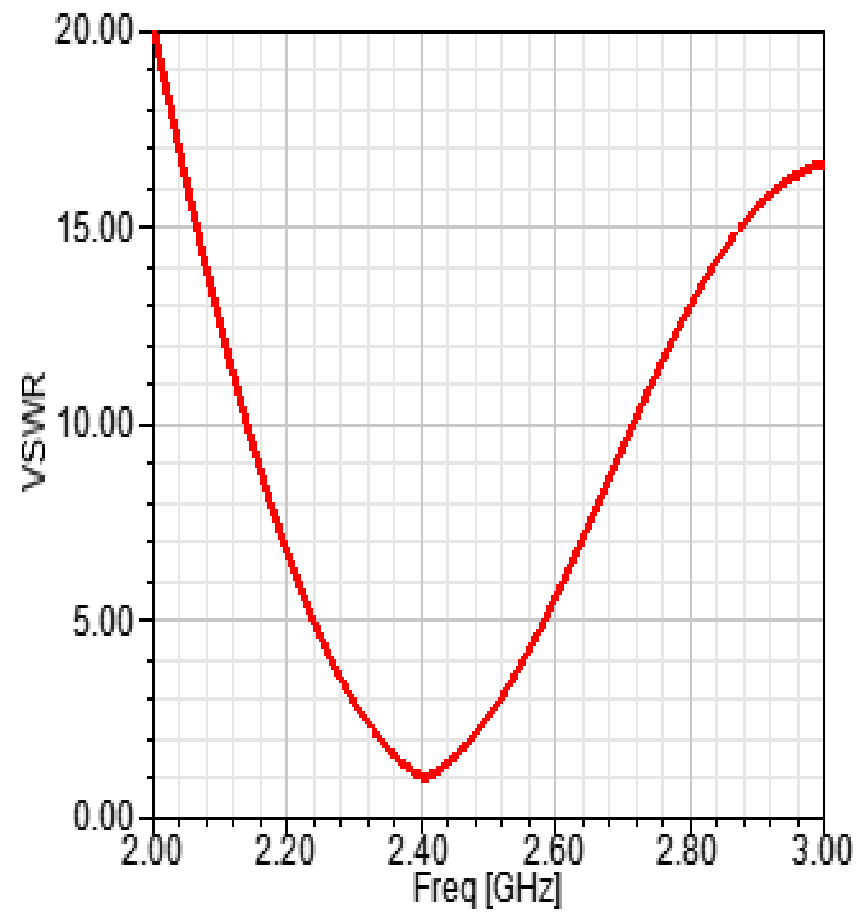

(a)

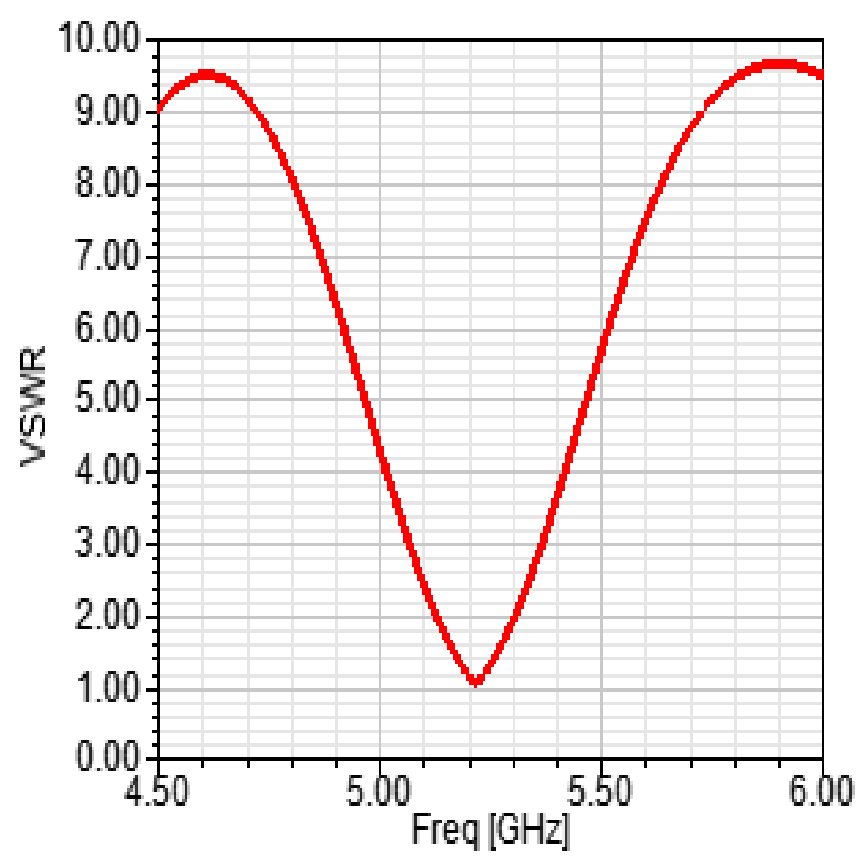

(b)

Fig. 5: Simulated VSWR characteristics

\section{Conclusion}

A synthesized circular microstrip patch antenna with parasitic opening sustained by microstrip line is intended to attain dual frequency exercise. The investigated circular patch and $\pi$ - space resonators operate at the primary band $(5.2 \mathrm{GHz})$ and secondary band $(2.4 \mathrm{GHz})$ subsequently. The antenna structure has been simulated and it is noticed that return loss of $-40 \mathrm{~dB},-27 \mathrm{~dB}$ at the recurrences of $2.39 \mathrm{GHz}$ and $5.25 \mathrm{GHz}$ subsequently. An arranged model configuration has small in size, less weight, reduced cost, acceptable isolation and sufficient operational bandwidth, with the end goal that it is suitable for WLAN applications.

\section{References}

[1] J. Liu, Q. Xue, H. Wong, H. W. Lai, Y. Long, "Design and analysis of a low-profile and broadband microstrip monopolar patch antenna", IEEE Trans. Antennas Propag., vol. 61, no. 1, pp. 11-18, Jan. 2013.

[2] Sekhar M, S. N. Bhavanam, Dr. P. Siddaiah, "Triple Frequency Circular Patch Antenna",IEEE International Conference on Intelligence and computing Research, pp. 1-3, December 2014.

[3] R. Srivastava, S. Ayub, V. K. Singh, J. P. Saini, "Dual Band Rectangular and Circular Slot Loaded Microstrip Antenna for WLAN/GPS/WiMax Applications",Fourth International Conference on Communication Systems and Network Technologies,pp. 45-48, April 2014.

[4] U. Chakraborty, A.Kundu,S.K.Chowdhury,A.K.Bhattacharjee, "Compact Dual-Band Microstrip Antenna for IEEE 802.11a WLANApplication", IEEE Antennas And Wireless Propogation Letters, Vol.13, pp.407-410, February2014.

[5] S. C. Gao, L. W. Li, T. S. Yeo, M. S. Leong,"Small DualFrequency Microstrip Antennas", IEEE Transactions on VehicularTechnology,vol.51,No.1,pp. 1916-1917, January 2002.

[6] H. A. Atallah, A. B. Abdel-Rahman, K.Yoshitomi, R. K.Pokharel,"Design of Dual Band-Notched CPW-Fed UWB Planar Monopole Antenna Using Microstrip Resonators”, Progress In Electromagnetics Research Letters, vol. 59, pp.51-56, 2016.

[7] M. Venkata Narayana, Govardhani.Immadi, Dr.Habibulla Khan, Y. Suraj, B. Hema Brahmani, P.S.V.S. Naveen Chowdary, M. Emmanuel Raju, "Enhancement Of Bandwidth Of Electrically SmallAntenna Using Spiral Resonator And Loop Feed", International Journal of Pure and Applied Mathematics, Volume 115 No. 7 2017, 471-476, ISSN: 1311-8080 (printed version); ISSN: 1314-3395 (on-line version).

[8] Govardhani.Immadi, Venkata Narayana, M., Reddy C.S.S., Sivani, P.J, Anil Kumar, P.V.S, "Design of uhf antenna for wireless applications using defective ground", ARPN Journal of Engineering and Applied Sciences Open Access Volume 11, Issue 17, 2016, Pages 10361-10364.

[9] J. A. Ansari, A. Mishra, N. P. Yadav,P. Singh, "Dualband Slot Loaded Circular Disk Patch Antenna for WLAN Application", International Journal Of Microwave And Optical Technology, vol.5, No.3, pp. 124-129, May 2010.

[10] Lakshmikanth, P., Takeshore, K., \& Madhav, B. T. P. (2015) Printed log-periodic dipole antenna with notched filter at 2.45 $\mathrm{GHz}$ frequency for wireless communication applications. Jour nal of Engineering and Applied Sciences, 10(3), 40-44. doi:10.3923/jeasci.2015.40.44

[11] M. I. Sabran, S. K. A. Rahim, M. F. M. Yusof, A. A. Eteng1, M. Z. M. Nor, I. M. Ibrahim,"Miniaturized Proximity Coupled Antenna with Slot Ring as Defected Ground Structure", IEEE Symposium on Wireless Technology and Applications (ISWTA), pp.81-85, Sept-oct 2014.

[12] G.P.Gao,M.Li,S.F.Niu,X.J.Li,B.N.Li,J.S.Zang, "Study Of Novel Wideband Circular Slot Antenna Having Frequency Band Notched Function",Progress In Electromagnetic Re$\operatorname{search}(P I E R) 96$, pp.141- 154,2009.

[13] C. J. Wang,S. W. Chang, "Studies On Dual-Band Multi-Slot Antennas",Progress In Electromagnetics Research, PIER, vol. 83 ,

Pp.293-306, 2008.

[14] J. S. Row and S. W. Wu. Circularly-polarized wide slot antenna loaded with a parasitic patch, IEEE Trans. Antennas Propag., vol. 56, pp. 2826-2832, Sept 2008.

[15] Zulkifli F. Y., Rodhaiah D., Rahardio E. T., Dual band microstrip antenna using $\mathrm{U}$ and $\mathrm{S}$ slot for WLAN applications, IEEE, Antenna and propagation society international sysmposium, pp. 2049-2052, June 2007.

[16] M. H. Tariq, S. Rashid, F. A. Bhatti,"Dual Band Microstrip PatchAntenna for WiMAX and WLAN Applications", International journal of Multidisciplinary and Currentresearch, vol.2,pp. 104-108, Jan/Feb 2014.

[17] Q. Zhong, Y. Li, H. Jiang, Y. Long,"Design of a Novel Dualfrequency Microstrip Patch Antenna for WLAN Applications",Antennas And Propogation Society International Symposium,vol.1, pp. 277-280,June 2004.

[18] R. A. Kranenburg and S. A. Long, , "Microstrip Transmission Line Excitation of Dielectric Resonator Antennas," Electron. Lett. vol. 24, pp.1156-1157, 1988. 
[19] C. A. Balanis, "Antenna Theory, Analysis and Design", Second edition, John Wiley andSons, NewYork, 1997.

[20] Lakshmikanth, P., Takeshore, K., \& Madhav, B. T. P. (2015) Printed log-periodic dipole antenna with notched filter at 2.45 $\mathrm{GHz}$ frequency for wireless communication applications. Jour nal of Engineering and Applied Sciences, 10(3), 40-44. doi:10.3923/jeasci.2015.40.44

[21] Madhav, B. T. P., Kaza, H., Kartheek, T., Kaza, V. L., Prasanth, S., Chandra Sikakollu, K. S. S., Bhavani, K. V. L. (2015). Novel printed monopole trapezoidal notch antenna with S-band rejection. Journal of Theoretical and Applied Information Technology, 76(1), 42-49. Retrieved from www.scopus.com 